\title{
Long-term oscillation of drought conditions in the western China: an analysis of PDSI on a decadal scale
}

\author{
JIN Jia ${ }^{1,2}$, WANG Quan ${ }^{1,3^{*}}$, LI Lanhai ${ }^{1}$ \\ ${ }^{1}$ Joint Research Center of Drylands, Xinjiang Institute of Ecology and Geography, Chinese Academy of Sciences, Urumqi \\ 830011, China; \\ ${ }^{2}$ University of Chinese Academy of Sciences, Beijing 100049, China; \\ ${ }^{3}$ Graduate School of Agriculture, Shizuoka University, Shizuoka 422-8529, Japan
}

\begin{abstract}
Water resource availability is one of the primary limiting factors with regard to ecosystems in the western China. Having a clear understanding of multi-scale drought patterns in this region is a key step for adaption and mitigation to climate change. The Palmer drought severity index (PDSI) is a widely applied index to assess drought conditions. In this study, long-term monthly self-calibrated PDSI data from 1951 to 2012 were examined for drought spatiotemporal variations in the western China. The results clearly indicated that apparent spatial heterogeneities were evidenced between two sub-regions (arid land with annual precipitation less than $200 \mathrm{~mm}$ and semiarid land with annual precipitation between 200 to $500 \mathrm{~mm}$ ) as well as in the entire region of the western China. Ensemble empirical mode decomposition (EEMD) analyses on monthly PDSI and other atmospheric variable time-series obtained from the Department of Civil and Environmental Engineering, Princeton University revealed that all monthly time-series of variables could be completely decomposed into eight intrinsic mode functions (IMFs) and a trend (residual). This indicates that the monthly PDSI and atmospheric variables of the semiarid area in the western China contain eight quasi-period oscillations on various timescale spanning, seasonal to decadal cycles and a trend of a larger timescale from 1951-2012. The multi-scale drought patterns identified in this research could be powerful supports for decision-making regarding coping with droughts in this region.
\end{abstract}

Keywords: decadal scale; EEMD; PDSI; arid land; semiarid land

Citation: JIN Jia, WANG Quan, LI Lanhai. 2016. Long-term oscillation of drought conditions in the western China: an analysis of PDSI on a decadal scale. Journal of Arid Land, 8(6): 819-831. doi: 10.1007/s40333-016-0089-5

Accumulating evidence suggests that global climate change is accelerating according to the most recent report from the Intergovernmental Panel on Climate Change (IPCC, 2013), which estimates that the globally averaged combined land and ocean surface temperature data increased with a linear warming trend at ca. $0.72^{\circ} \mathrm{C}$ in $1951-2012$ (Stocker et al., 2013). Although the warming trend varied considerably in both spatial and temporal contexts, it was particularly strong in the cold season (November to March) with an increase of $2.4^{\circ} \mathrm{C}$ per 50 years in the mid-latitude semiarid area of Asia, where the annual precipitation was 200 to $600 \mathrm{~mm}$ during 1901-2009 (Huang et al., 2012). Similarly, it was reported that patterns of precipitation have also been changing: arid and semiarid regions are becoming drier while other areas, especially mid-to-high latitudes, are becoming wetter. Moreover, it is clear that all components of the climate system are undergoing further changes.

Arid land, which covers about 30\% of the Earth's surface, is highly vulnerable to climate change

*Corresponding author: WANG Quan (E-mail: qw4academic@gmail.com)
Received 2015-12-12; revised 2016-04-26; accepted 2016-05-21
(C) Xinjiang Institute of Ecology and Geography, Chinese Academy of Sciences, Science Press and Springer-Verlag Berlin Heidelberg 2016 
with less available water and a dramatic expanding of water consumption (Li et al., 2007). Central Asia accounts for a large proportion of global arid land area and is characterized by extremely low precipitation, fluctuating humidity and high summer temperatures (Zheng and Wang, 2014). Water resource availability is the primary limiting factor with regard to the ecosystem in this region (Fang et al., 2013), in which drought and water scarcity apparently have significant impacts on agricultural, ecological and economic development (Geng et al., 2014).

Assessing drought severity is not a straightforward and easy task for it is dependent not only on the duration, intensity and geographical extent of a specific drought episode but also on the demands made by human activities and by the vegetation on a region's water supplies (Wilhite and Glantz, 1985). Among drought assessment approaches, drought indices are indispensable tools to detect, monitor and evaluate drought events (Niemeyer, 2008). A drought index used for assessment should be able to quantify: (1) the moisture condition of a region and, thereby, to detect the onset and measure the severity of drought events; and (2) the spatial extent of a drought event, thereby, allowing a comparison of moisture supply conditions between regions (Alley, 1984; Quiring and Papakryiakou, 2003).

Various drought indices, each having a variety of data input requirements, were developed to quantify drought (Quiring and Papakryiakou, 2003), for example, the Palmer drought severity index (PDSI) (Palmer, 1965), the rainfall anomaly index (RAI) (Van Rooy, 1965), the crop moisture index (CMI) (Palmer, 1968), the Bhalme-Mooley index (BMDI) (Bhalme and Mooley, 1980), the NOAA drought index (NDI) (Titlow, 1987) and the standardized precipitation index (SPI) (McKee et al., 1993, 1995). Among these indexes, the PDSI is the most prominent one, which can be attributed to the fact that it provides decision makers with a measurement of the abnormality of recent weather for a region, an opportunity to place current conditions in historical perspective and spatial and temporal representations of historical droughts (Alley, 1984; Agwata, 2014). The PDSI has been widely used for a variety of applications in drought monitoring and quantifying long-term aridity changes (Zhai and Pan, 2003; Zou et al., 2005; Zhai et al., 2010; Dai, 2011a). A number of previous studies have proved its applicability in northern China (Wei et al., 2003; Zhang et al., 2007).

Previous index-based studies on precipitation/evapotranspiration mainly focused on seasonal or annual scale drought in northern China since the 1950s (Li et al., 2006; Ding et al., 2013; Huo et al., 2013; Li et al., 2013; Li et al., 2014). However, most recently, it has been proposed that, in addition to robust multi-decadal warming, global mean surface temperature exhibits substantial decadal and interannual variability (Stocker et al., 2013). Furthermore, strong decadal and interannual moisture variations in China during 1951-2005 were also reported (Li et al., 2009). Accordingly, as a result of climate change, drought may exhibit decadal and interannual oscillations as well. Long-term continuous drought could produce a more complex web of impacts on ecology, economy and society. Thus, long-term variation patterns should be classified to mitigate any possible impacts.

The main objectives of the study were to: (1) reveal the trend of drought in recent decades in the western China; (2) examine multi-decadal oscillation patterns of drought in the western China; and (3) explore the effects of climate factors (precipitation, total incident solar radiation, surface air temperature and specific humidity) on multi-decadal oscillation patterns of drought in the western China. The western China, in this study, was defined as the region with mean annual precipitation below $500 \mathrm{~mm}$, including both arid and semiarid areas.

\section{Materials and methods}

\subsection{Study area}

Arid and semiarid land in the western China covers an area of $5.2 \times 10^{6} \mathrm{~km}^{2}$, accounted for nearly half the territory of China. This region is severely drought prone with an annual precipitation less than $500 \mathrm{~mm}$ (Zheng and Wang, 2014). The elevation of this region ranges from -179 to 8,614 $\mathrm{m}$. Different ecosystems, e.g. croplands, forests, shrub lands, grasslands and deserts, are included in 
this region. Recent rapid population growth and migration to the marginal semiarid and arid areas exacerbated the land degradation and water depletion in this region (Huo et al., 2013). Traditionally, this region was further separated into two sub-regions defined as arid land and semiarid land according to the annual precipitation (<200 and 200-500 mm, respectively; Fig. 1).

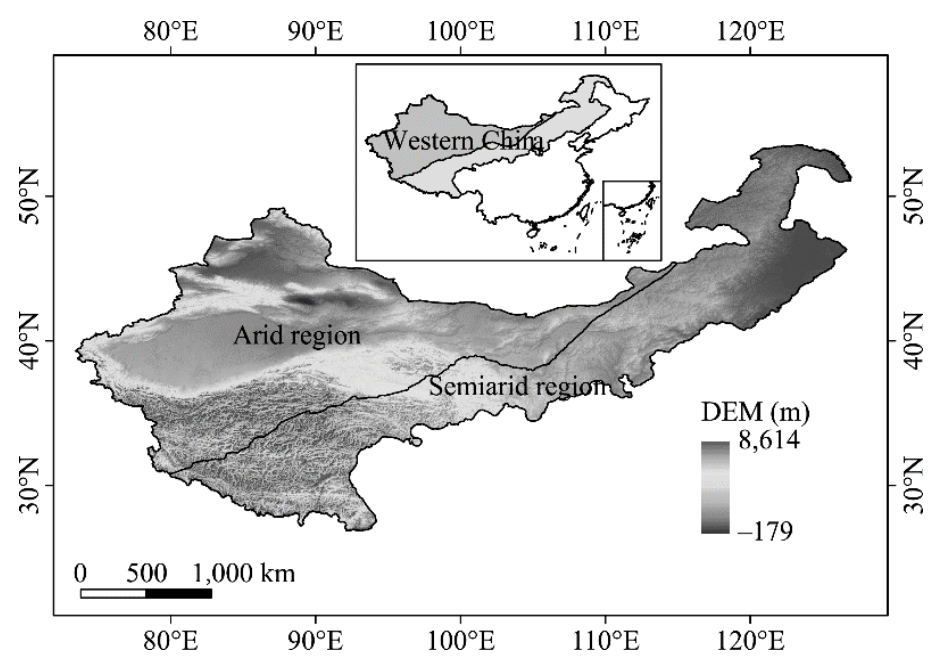

Fig. 1 Location of the study areas based on digital elevation model (DEM)

\subsection{PDSI and climate parameters}

The PDSI has been proven to be the most effective way in determining long-term drought (Palmer, 1965; Alley, 1984). The PDSI is a standardized measure with values varying roughly in -6.0-6.0. A score of zero is considered normal and a drought is shown in terms of negative numbers while wetness is shown with positive values. PDSI values below -2.0 represent moderate to extreme drought, for example, -2.0 is moderate drought, -3.0 is severe drought and -4.0 is extreme drought (Palmer, 1965; Dai, 2011a).

The PDSI is a soil moisture algorithm calculated using precipitation and temperature data as well as the locally available water content of the soil. From the inputs, all the basic terms of the water balance equation can be determined including evapotranspiration, soil recharge, and runoff and moisture loss from the surface layer (Agwata, 2014).

PDSI data used in this study are monthly, self-calibrated PDSI with potential evapotranspiration estimated using the sophisticated Penman-Monteith equation based on historical data (Dai, 2011a, b, 2013). An updated version of these data from 1951-2012 (http://www.cgd.ucar.edu/cas/catalog/climind/pdsi.html) were used in this study. The data are organized into $2.5^{\circ} \times 2.5^{\circ}$ grids and globally cover the land area from $60^{\circ} \mathrm{S}$ to $77.5^{\circ} \mathrm{N}$. These data were calculated from observed monthly precipitation and surface air temperature data of 1850-2010, and were self-calibrated using local climate conditions instead of the (fixed) coefficients used by Palmer (1965) based on data from the central United States, which is claimed to be more spatially comparable than the original PDSI (Dai, 2011a; Qian and Zhou, 2013).

Additionally, monthly climatic factors including precipitation (PRECT), total incident solar radiation (FSDS), surface air temperature (TBOT) and specific humidity (QBOT) provided by the Department of Civil and Environmental Engineering, Princeton University (http://hydrology.princeton.edu/data.pgf.php) were also used in this study. This dataset blends reanalysis data with observations and disaggregates in time and space, which can be used to drive models of the terrestrial hydrologic and ecological processes for the study of seasonal and interannual climate variability (Sheffield et al., 2006). 


\subsection{Ensemble empirical mode decomposition}

The ensemble empirical mode decomposition (EEMD) method is similar to the windowed Fourier transformation or wavelet transformation, but is more suitable for analyzing nonlinear and nonstationary time-series (Liu et al., 2014). It is an adaptive data analysis method to decompose any complicated data series into a finite and often small number of amplitude-frequency modulated oscillatory components, including intrinsic mode functions (IMFs) and residual (RES) (Qian et al., 2011). In this study, the EEMD method has been applied to decompose the monthly PDSI or atmospheric variables into various time-scale components from 1951 to 2012.

The principle of EEMD is simple as the added white noise would populate the time-frequency space uniformly with the constituting components at different scales. When the signal is added to this uniform background, the bits of signals of different scales are automatically projected onto proper scales of reference established by the white noise. Although each individual trial may produce very noisy results, the noise in each trial is canceled out in the ensemble mean of enough trials and the ensemble mean is treated as the true answer (Huang and $\mathrm{Wu}, 2008$; Wu and Huang, 2009).

The main steps of the EEMD analysis can be illustrated as follows: (1) adding a white noise series to the targeted data; (2) decomposing the data with added white noise into IMFs; (3) repeating the steps 1 and 2 over and over with a different white noise series each time; and (4) obtaining the (ensemble) means of corresponding IMFs of the decompositions as the final result (Huang and Wu, 2008). More details concerning the EEMD analysis can be found Huang and Wu (2008) and Wu and Huang (2009).

\section{Results}

\subsection{PDSI patterns}

According to the classification of wet and dry periods based on PDSI (Palmer, 1965), the percentage frequency of each class, which represents a certain degree of drought, of the western China, as well as in the two sub-regions during 1951-2012, were calculated and illustrated in Fig. 2, which shows the percentages of PDSI frequency in arid and semiarid regions, and of the western China as well.

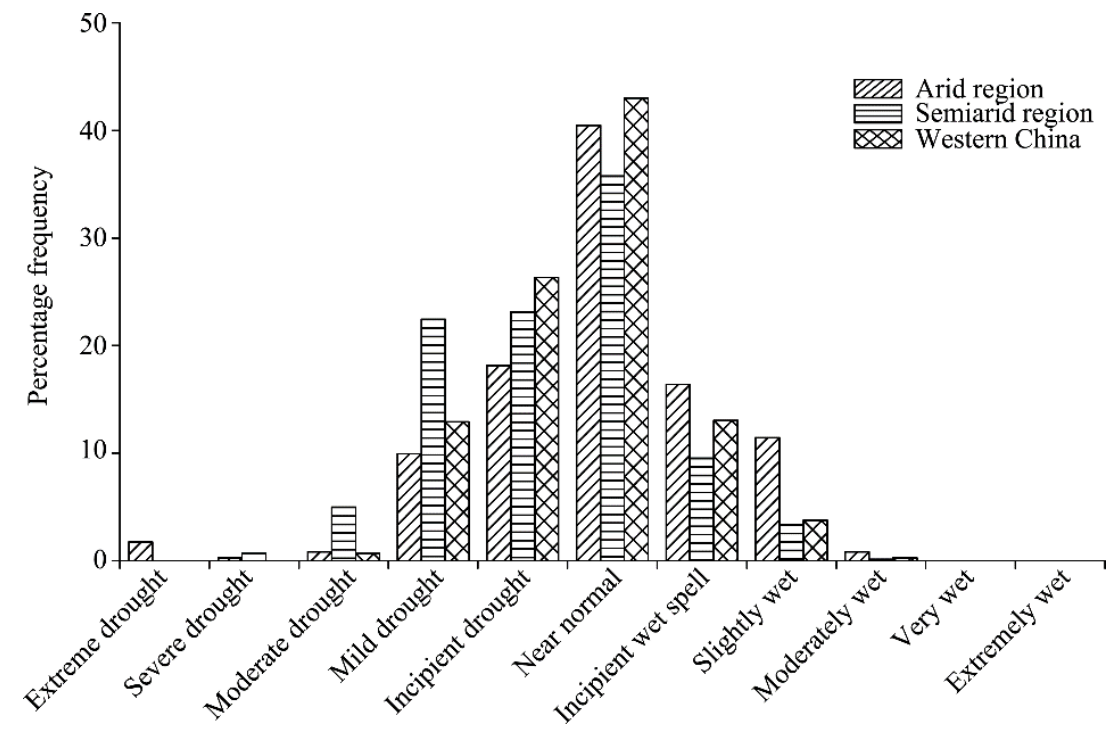

Fig. 2 Histogram of monthly Palmer drought severity index (PDSI) of the western China and the two sub-regions

A normal distribution of PDSI during 1951-2012 was recognized for the western China, in which about $60 \%$ of PDSI showed negative values, representing dry periods. Similar distributions with the central frequency near zero were also noted for the two sub-regions. Even so, there existed 
some discrepancies among different regions. About $10 \%$ of mild drought and $18 \%$ of incipient drought periods were identified for the arid region where the annual precipitation is $<200 \mathrm{~mm}$. As a comparison, in the semiarid region with the annual precipitation between $200-500 \mathrm{~mm}$, the percentage frequency of mild drought periods and incipient drought periods reached $22 \%$ and $23 \%$, respectively. What's more, much more extreme drought periods (2\%) were identified for the arid region while more severe drought and moderate drought periods were identified for the semiarid region, reaching about $1 \%$, and $5 \%$, respectively.

Long-term variation patterns of spatially statistical PDSI are illustrated in Fig. 3, which shows the box and whisker plots of annual PDSI values calculated using monthly PDSI of the western China in 1951-2012. The line inside the boxes represents the median and the cross mark inside the boxes represents the average values. The upper and lower lines of the boxes indicate the $75^{\text {th }}$ and $25^{\text {th }}$ percentiles, respectively. Furthermore, the upper and lower parts of the whiskers indicate the respective maximum and minimum values of the PDSI. Outliers are data with values beyond the ends of the whiskers.

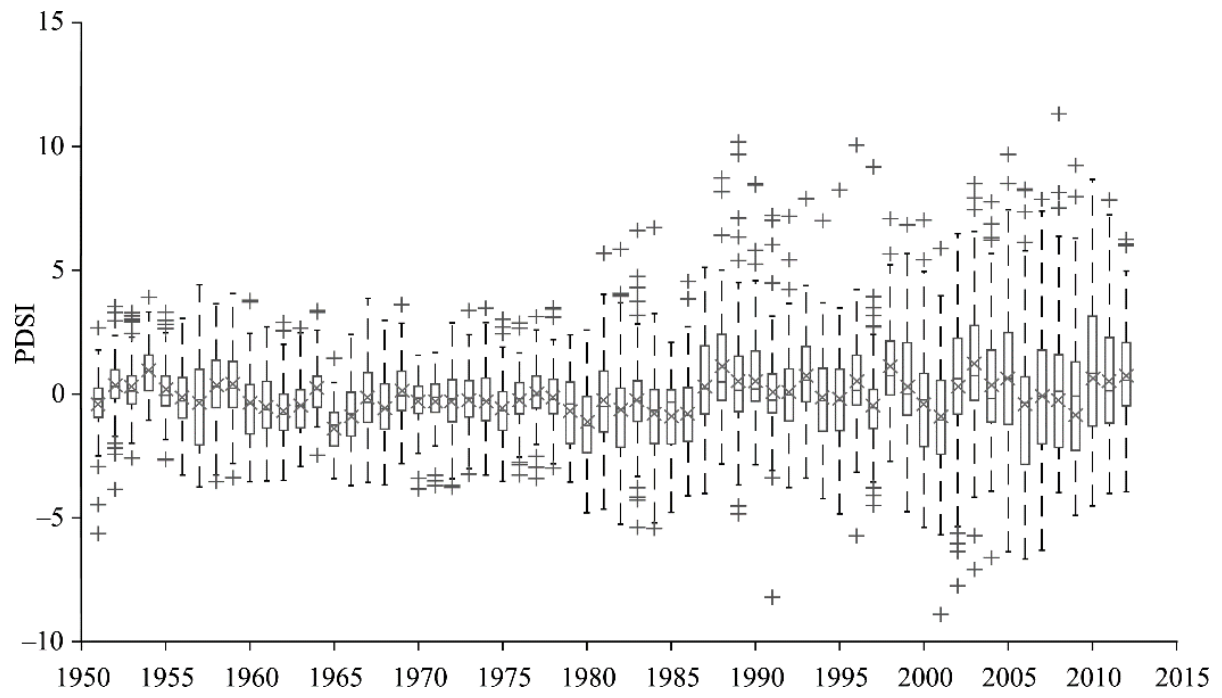

Fig. 3 Box and whisker plots of annual PDSI values in the western China in 1951-2012

It is clear that the annual averaged PDSI of the western China varied from about -6.6 to 8.7 during the analysis period. The annual spatially averaged PDSI fluctuated between -1.4 and 1.2, with the minimum and maximum PDSI values in 1965 and 2003, respectively.

There are great differences between the lower and upper parts of the whiskers (especially after 1987). Additionally, many PDSI outliers can be identified in Fig. 3, which generally represent extreme events in specific areas (cells). These suggest that great spatial heterogeneity of PDSI can be captured in the western China and PDSI patterns in different separated spatial regions should be discussed.

\subsection{Multi-scale temporal variation patterns of spatially averaged PDSI}

\subsubsection{The western China in its entirety}

The temporal variation of spatially averaged PDSI in the western China during 1951-2012 is shown in Fig. 4a. Wetter periods can be identified before 1965 and during 1986-2005. Extreme drought events were apparent in 1966, 2007 and 2010 as PDSI values were lower than -2.0.

Figure 4 shows that the PDSI is completely decomposed into eight modes (IMFs) and a trend (RES) by the EEMD method. Each IMF component denotes the variation at different timescales. It clearly indicates that the monthly PDSI variation of the western China contains eight quasi-period oscillations at different timescales during 1951-2012, with a decreasing trend before 1990 and an increasing trend after 1990. Table 1 presents the cycles of variance contribution rates 
of the Intrinsic Mode Functions (IMFs) decomposed from the monthly PDSI time-series in the western China and their correlation coefficients with the monthly PDSI time-series. The first and second IMFs were apparently standing for the monthly and seasonal variations of PDSI. For longer time scales ( $>1$ year), the third to the eighth IMFs represented different periods of 1.5, 3.0, 5.4, $12.4,25.0$ and 60.0 years, respectively, with relative variance contribution rates of $15.03 \%, 20.01 \%$, $18.56 \%, 14.63 \%, 5.95 \%$ and $2.58 \%$, respectively. This suggests that the temporal variation of spatially averaged PDSI was jointly determined by IMF3, IMF4, IMF5 and IMF6 with an accumulated variance contribution rate of about $70 \%$.
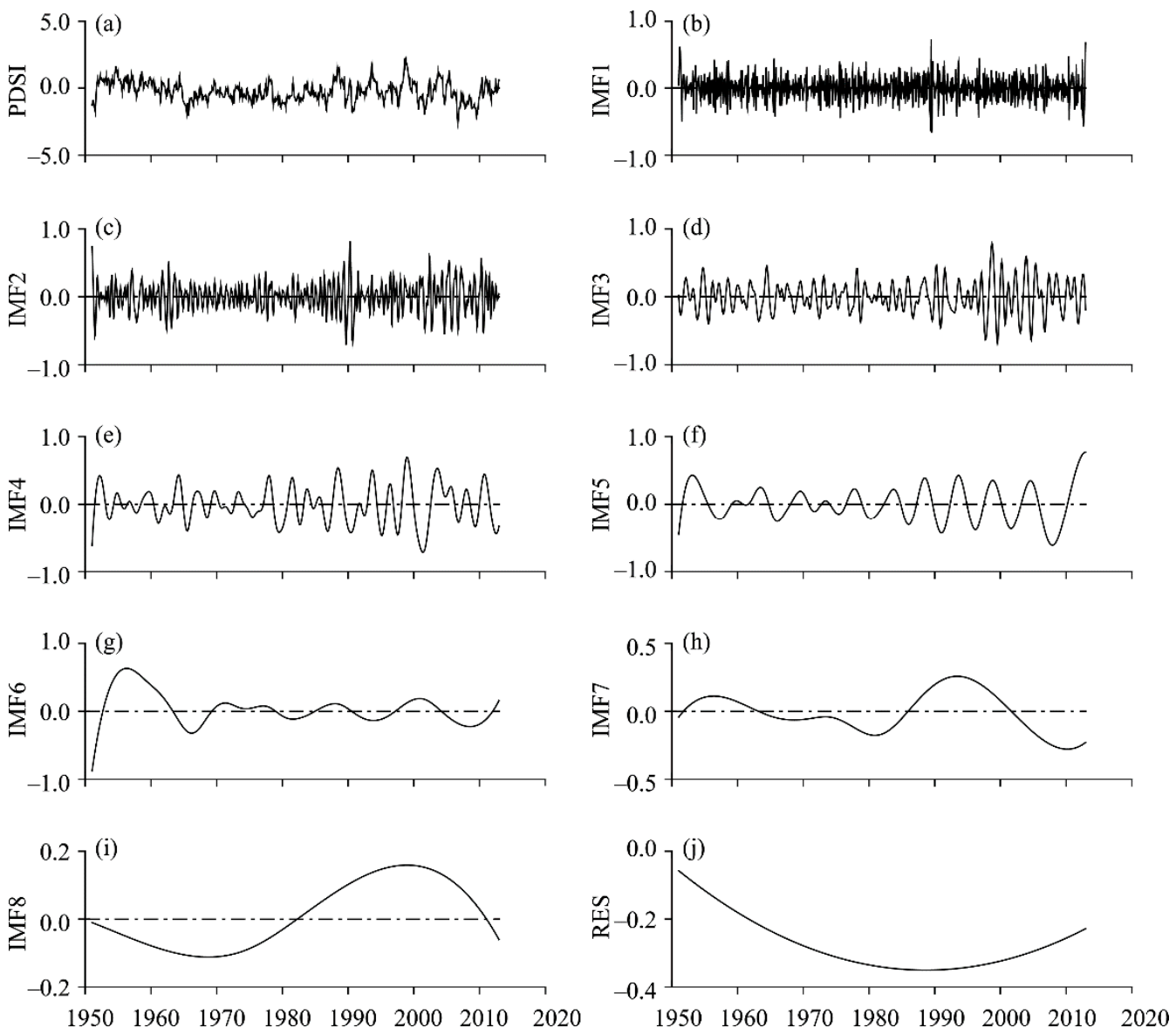

Fig. 4 The intrinsic mode functions (IMFs) and a trend (RES) obtained from PDSI values in the western China

Table 1 The cycles of variance contribution rates of the intrinsic mode functions (IMFs) decomposed from the monthly PDSI time-series in the western China and their correlation coefficients with the monthly PDSI time-series

\begin{tabular}{cccccccccc}
\hline IMFs & IMF1 & IMF2 & IMF3 & IMF4 & IMF5 & IMF6 & IMF7 & IMF8 & RES \\
\hline Cycles (a) & - & - & 1.5 & 3.0 & 5.4 & 12.4 & 25.0 & 60.0 & - \\
$R^{2}$ & 0.0845 & 0.2119 & 0.2874 & 0.336 & 0.2923 & 0.1726 & 0.1095 & 0.0038 & 0.0492 \\
VC (\%) & 10.14 & 13.1 & 15.03 & 20.01 & 18.56 & 14.63 & 5.95 & 2.58 & 0.00 \\
\hline
\end{tabular}

Note: VC, variance contribution rate; -, data not available.

\subsubsection{Arid region}

As with the arid region only, the temporal variation of spatially averaged PDSI during the period is shown in Fig. 5a. The results show that arid land in the western China was affected by more severe drought from 1960 to 1985, as PDSI values were relatively low. Extreme drought events were apparent around 2009 with PDSI values lower than -5.0.

EEMD revealed that the temporal variation of spatially averaged PDSI of the arid region also 
contains eight quasi-period oscillations at different timescales and a mild decreasing trend during the period (Fig. 5). Table 2 presented the cycles of variance contribution rates of the IMFs decomposed from the monthly PDSI time-series of this area and their correlation coefficients with the monthly PDSI time-series. For a scale longer than one year, the third to eighth IMFs have about 1.4-, 2.8-, 5.0-, 10.0-, 35.0- and 62.0-a periods with variance contribution rates of 16.07\%, 22.95\%, $13 \%, 7.97 \%, 6.34 \%$ and $22.47 \%$, respectively.
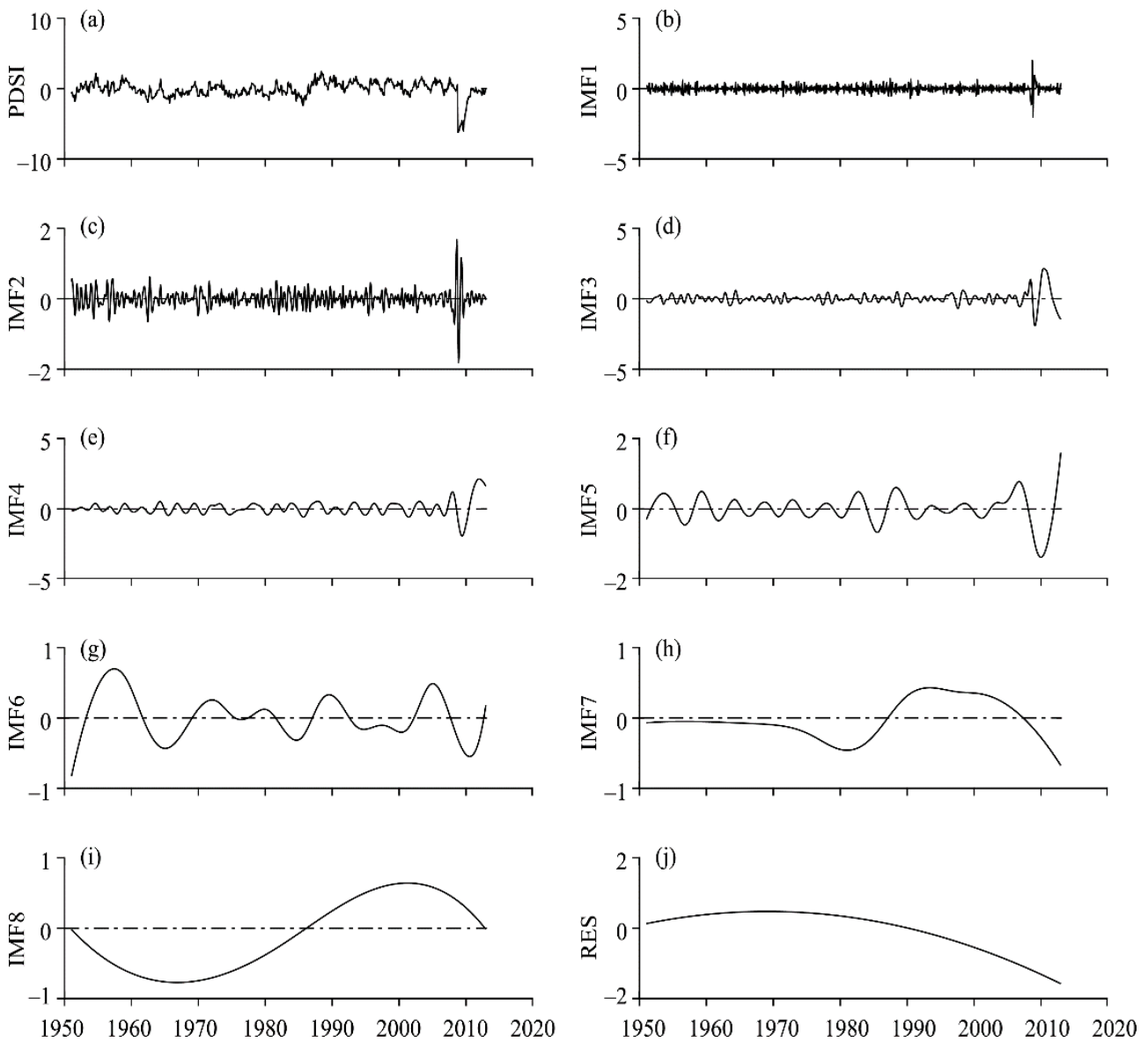

Fig. 5 The IMFs obtained from PDSI values of the arid area in the western China

Table 2 The cycles of variance contribution rates of the IMFs decomposed from the monthly PDSI time-series of the arid area in the western China and their correlation coefficients with the monthly PDSI time-series

\begin{tabular}{cccccccccc}
\hline IMFs & IMF1 & IMF2 & IMF3 & IMF4 & IMF5 & IMF6 & IMF7 & IMF8 & RES \\
\hline Cycles (a) & - & - & 1.5 & 3.0 & 5.4 & 12.4 & 25.0 & 60.0 & - \\
$R^{2}$ & 0.0325 & 0.0999 & 0.0975 & 0.2424 & 0.3186 & 0.1837 & 0.1557 & 0.0389 & 0.0046 \\
VC (\%) & 5.76 & 5.44 & 16.07 & 22.95 & 13 & 7.97 & 6.34 & 22.47 & 0 \\
\hline
\end{tabular}

Note: VC, variance contribution rate; -, data not available.

\subsubsection{Semiarid region}

Similarly, the temporal variation of spatially averaged monthly PDSI of the semiarid area in the western China during 1951-2012 is shown in Fig. 6a. Wetter period can be clearly seen before 1965. Extreme drought events occurred in year 2002 and year 2007 during the long-term drought period after 1980 .

The EEMD analysis suggested that the temporal variation of spatially averaged monthly PDSI in this region was also decomposed into eight modes (IMFs) and a trend (RES), indicating similar eight quasi-period oscillations and a decreasing trend of larger timescale during 1951-2012 (Fig. 
6). Table 3 presented the cycles of variance contribution rates of different IMFs decomposed from the monthly PDSI time-series of the semiarid area only in the western China and their correlation coefficients with the monthly PDSI time-series. For scales longer than one-year, the third to eighth IMFs have about 1.5-, 2.7-, 5.2-, 11.0-, 18.0- and 35.0-a periods with variance contribution rates of $18.59 \%, 25.45 \%, 10.95 \%, 5.69 \%, 5.61 \%$ and $0.45 \%$, respectively.
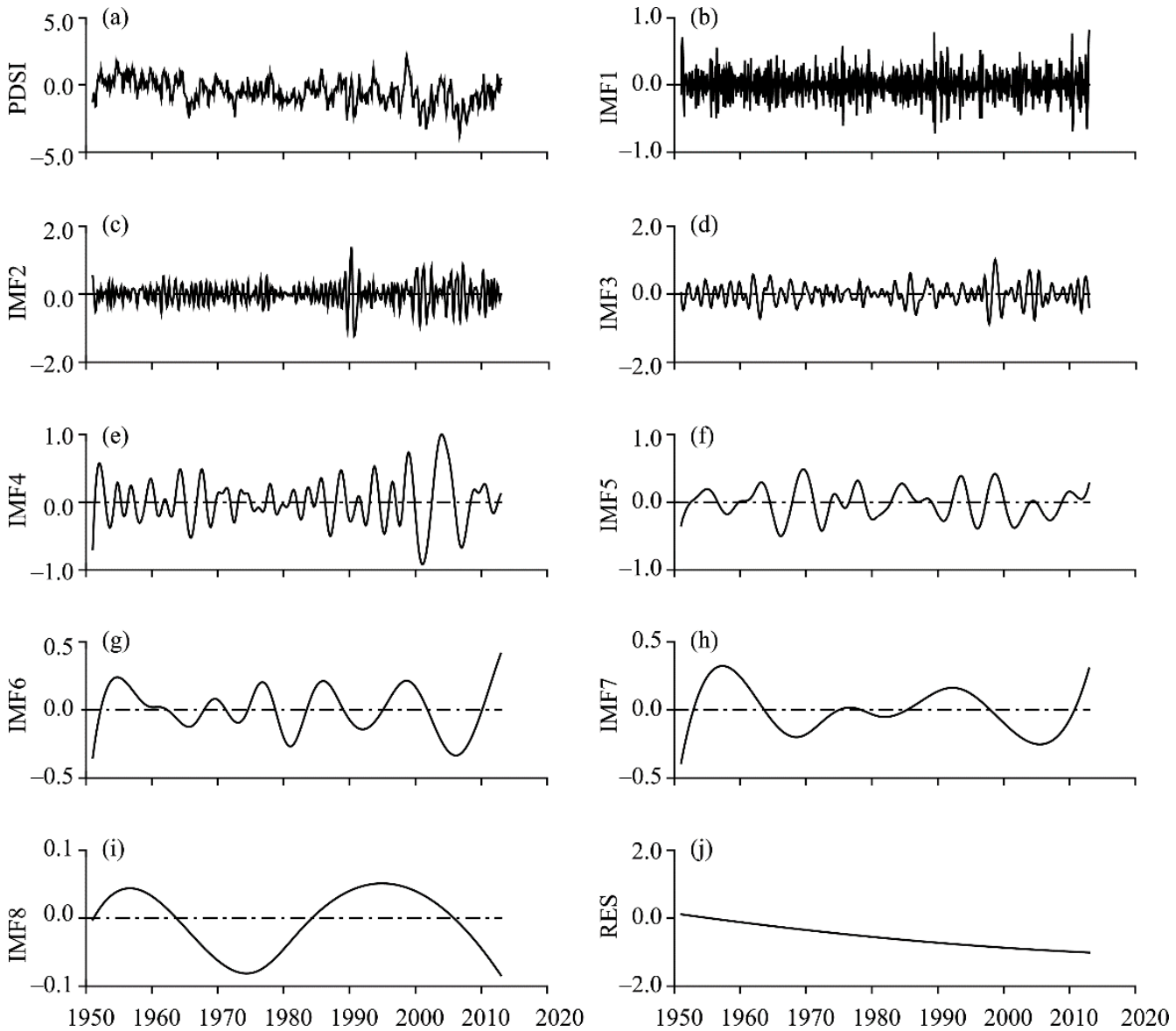

Fig. 6 The IMFs obtained from PDSI of semiarid area in the western China

Table 3 The cycles of variance contribution rates of the IMFs decomposed from the monthly PDSI time-series of semiarid area in the western China and their correlation coefficients with the monthly PDSI time-series

\begin{tabular}{ccccccccccc}
\hline IMFs & IMF1 & IMF2 & IMF3 & IMF4 & IMF5 & IMF6 & IMF7 & IMF8 & RES \\
\hline Cycles (a) & - & - & 1.5 & 2.7 & 5.2 & 11 & 18 & 35 & - \\
$R^{2}$ & 0.1024 & 0.2633 & 0.316 & 0.3037 & 0.2869 & 0.1167 & 0.0791 & 0.0007 & 0.0855 \\
VC (\%) & 11.2 & 22.06 & 18.59 & 25.45 & 10.95 & 5.69 & 5.61 & 0.45 & 0 \\
\hline
\end{tabular}

Note: VC, variance contribution rate; -, data not available

\section{Discussion}

\subsection{Diversity of drought trends}

Current results clearly show that different drought trends existed when the western China and different sub-regions were considered. Although spatially averaged monthly PDSI time-series may be decomposed into eight IMFs for both the western China and two distinctive sub-regions, the cycles of each IMF are different. In addition, the statistics of percentage frequency of dry and wet periods also deployed diverse patterns when different areas were considered. 
Apparently, topography in different regions contributed to the diversity. It was convincing that topography exerted a strong dynamic force on the atmospheric circulations; and the land surface exchanged momentum, energy, water and chemical constituents with the atmosphere (Giorgi et al., 2003). Besides, land-use and land-cover change was also suggested as an important factor that controlled water resources in both local and global scales for plants, which can reverse warming effects on the ecosystem-waterbalance (Zavaleta et al., 2003; Liu et al., 2008). In the western China, land surfaces are characterized by intense spatial heterogeneity. The elevation across the whole region is from -179 to $8,614 \mathrm{~m}$, with the arid region from -179 to $8,179 \mathrm{~m}$ and the semiarid region from 33 to $8,614 \mathrm{~m}$.

To reveal the topographic distinction between the two sub-regions, we illustrated the histograms of the digital elevation model (DEM) of the two sub-regions in Fig. 7, from which the distinctions in the elevation for the arid and semiarid regions can be captured. The area in the arid region with the elevation from 1,500 to 3,500 m covers $23 \%$ area of this region, which is much larger than the percentation of this area zone in the semiarid region (13\%). The minimum and maximum in elevation of this zone are approximate to the lower and upper timberlines in the arid area of Central Asia (Troll, 1973; Dai, 1999; Wang et al., 2004; Geping et al., 2011).

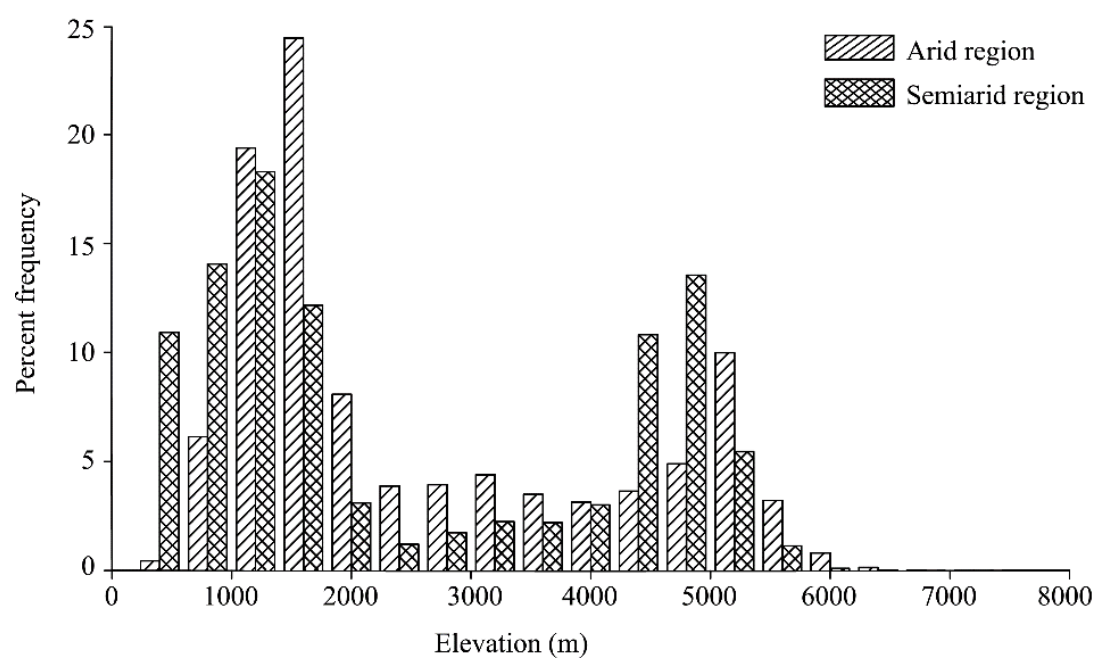

Fig. 7 Histogram of elevation values of a DEM of two sub-regions in the western China

Similarly, different proportions of four main ecosystems (cropland, grassland, forest and desert) in the two sub-regions clearly revealed the ecosystem distribution diversities of the regions. Large areas of grasslands are distributed in the semiarid region, covers about $56 \%$ of this region. More croplands, grasslands and forests are distributed in the semiarid land than those in the arid land, while the desert covers about $41 \%$ of the arid region. Thus, diversities of ecosystem distribution in the arid and semiarid regions should be another important factor contributing to the diversity of PDSI patterns derived from EEMD in these two sub-regions.

\subsection{Potential climate factors causing long-term drought changes}

To explore the primary effects of atmospheric variables leading to different long-term scale variations of PDSI in the western China as well as in the two sub-regions, we used the monthly reanalysis derived data, including PRECT, FSDS, TBOT and QBOT data of 1951-2012. First, they were decomposed into various time-scale components. Then the pre-whitening procedure was applied to each component derived from EEMD to remove the serial correlation (Von Storch, 1999; Yue et al., 2002; Bayazit and Önöz, 2007) before a correlation analysis on the decomposed IMFs and residual of atmospheric variables. PDSI was conducted to determine the effects of each variable on PDSI in each time-scale. 
Eight similar IMFs and a trend (RES), ignorant of different regions considered (the western China and the two sub-regions), were identified from the EEMD analyses for monthly atmospheric variable during that period. The correlation coefficients between PDSI and atmospheric variables of monthly time-series and each IMF derived from EEMD in the western China are presented in Table 4. No significant correlation can be identified on the monthly to annual scale (monthly timeseries, IMF1, IMF2) between PDSI and all atmospheric variables. Substantial correlations can be captured on over one-year scales (IMF1 to IMF8) between PDSI and some atmospheric variables. On about 1.5- (IMF3) and 5.4-a scales (IMF5), QBOT is the main positive factor causing the patterns of PDSI (correlation coefficient, 0.29 and 0.17, respectively). On 3.0-a scale (IMF4), PRECT and QBOT show positive impacts on PDSI. The TBOT, QBOT and PRECT show corresponding correlations with PDSI on 12.4-a scale with correlations of 0.63, 0.46 and 0.54 , respectively. For the long-term timescale (RES), PDSI is significantly and negatively correlated with PRECT and TBOT.

Table 4 Correlation coefficients between PDSI and atmospheric variables on time scales in the western China

\begin{tabular}{lcccccccccc}
\hline & Monthly & IMF1 & IMF2 & IMF3 & IMF4 & IMF5 & IMF6 & IMF7 & IMF8 & RES \\
\hline PRECT & 0.03 & $0.13^{* *}$ & -0.03 & $0.08^{*}$ & $0.40^{* *}$ & $0.13^{* *}$ & $0.63^{* *}$ & $0.22^{* *}$ & $0.90^{* *}$ & $-0.96^{* *}$ \\
FSDS & 0.00 & $-0.07^{*}$ & 0.03 & 0.03 & $-0.08^{*}$ & $-0.17^{* *}$ & $0.25^{* *}$ & $0.20^{* *}$ & $0.71^{* *}$ & 0.30 \\
TBOT & -0.03 & $-0.10^{* *}$ & -0.03 & -0.01 & 0.00 & $-0.21^{* *}$ & $0.46^{* *}$ & $0.36^{* *}$ & $0.15^{* *}$ & $-0.84^{* *}$ \\
QBOT & 0.01 & -0.02 & -0.02 & $0.29^{* *}$ & $0.38^{* *}$ & 0.17 & 0.54 & $0.27^{* *}$ & 0.60 & $0.11^{* *}$ \\
\hline
\end{tabular}

Note: ${ }^{*}$, significance level at $P<0.05 ;{ }^{* *}$, significance level at $P<0.01$; PRECT, precipitation; FSDS, total incident solar radiation; TBOT, surface air temperature; QBOT, specific humidity.

Table 5 presents the correlation analysis results for the arid region, where, at 5.0-a scale (IMF5), the QBOT is also the main factor causing the pattern of PDSI (correlation coefficient, 0.55). At 1.4(IMF3) and 2.8-a (IMF4) scales, PDSI is negatively correlated with TBOT. At 10.0- (IMF6) and 62.0-a (IMF8) scales, PRECT shows higher correlation coefficients with PDSI than any other variables. The temporal variation of PDSI at 35.0-a (IMF7) scale is patterned by joint effects of FSDS, QBOT and TBOT.

Table 5 Correlation coefficients between PDSI and atmospheric variables on time scales in arid land

\begin{tabular}{lcccccccccc}
\hline & Monthly & IMF1 & IMF2 & IMF3 & IMF4 & IMF5 & IMF6 & IMF7 & IMF8 & RES \\
\hline PRECT & $0.09^{*}$ & $0.17^{* *}$ & 0.07 & 0.00 & $0.18^{* *}$ & $0.27^{* *}$ & $0.49^{* *}$ & $-0.23^{* *}$ & $0.98^{* *}$ & $0.88^{* *}$ \\
FSDS & 0.01 & $-0.07^{*}$ & 0.06 & -0.06 & $-0.24^{* *}$ & $-0.30^{* *}$ & 0.01 & $0.82^{* *}$ & $0.61^{* *}$ & 0.95 \\
TBOT & 0.00 & $-0.11^{* *}$ & 0.05 & $-0.34^{* *}$ & $-0.31^{* *}$ & $0.08^{*}$ & $0.49^{* *}$ & $0.73^{* *}$ & $-0.92^{* *}$ & $-0.77^{* *}$ \\
QBOT & 0.04 & 0.00 & 0.06 & 0.06 & $0.22^{* *}$ & $0.55^{* *}$ & $0.41^{* *}$ & $0.63^{* *}$ & 0.96 & -0.05 \\
\hline
\end{tabular}

Note: ${ }^{*}$, significance level at $P<0.05 ;{ }^{* *}$, significance level at $P<0.01$.

The results for the semiarid region are presented in Table 6. At the 1.5-a scale (IMF3), QBOT remains the main factor causing the pattern of PDSI. At the 1.5-a scale (IMF3), QBOT is the main factor causing the pattern of PDSI (correlation coefficient, 0.15). At the 5.2-a scale (IMF5), PRECT shows much higher correlation coefficient value with PDSI than any other variables. In addition, PRECT exhibited the most critical impact at the 18.0-a scale (IMF7) variation of PDSI with a correlation coefficient of 0.9 . At the 2.7-a scale (IMF4), PDSI had significant and positive correlations with PRECT and QBOT. QBOT also had a significant impact on 11.0- (IMF6) and 35.0-a (IMF8) scales’ PDSI oscillations.

Table 6 Correlation coefficients between PDSI and atmospheric variables on time scales in semiarid land

\begin{tabular}{lcccccccccc}
\hline & Monthly & IMF1 & IMF2 & IMF3 & IMF4 & IMF5 & IMF6 & IMF7 & IMF8 & RES \\
\hline PRECT & 0.03 & $0.18^{* *}$ & -0.05 & 0.03 & $0.32^{* *}$ & $0.44^{* *}$ & $0.21^{* *}$ & $0.90^{* *}$ & $-0.11^{* *}$ & $-0.94^{* *}$ \\
FSDS & 0.01 & $-0.07^{*}$ & 0.04 & -0.02 & -0.06 & $-0.07^{*}$ & $0.12^{* *}$ & 0.04 & $0.48^{* *}$ & 1.00 \\
TBOT & -0.05 & $-0.08^{*}$ & -0.04 & -0.02 & -0.07 & $-0.25^{* *}$ & 0.05 & $-0.21^{* *}$ & $0.58^{* *}$ & $-0.99^{* *}$ \\
QBOT & 0.01 & -0.01 & -0.06 & $0.15^{* *}$ & $0.38^{* *}$ & $0.11^{* *}$ & $0.21^{* *}$ & $0.15^{* *}$ & 0.59 & $0.99^{* *}$ \\
\hline
\end{tabular}

Note: ${ }^{*}$, significance level at $P<0.05 ;{ }^{* *}$, significance level at $P<0.01$. 


\subsection{Usage of identified long-term scale drought patterns}

Water is one of the major constraints in arid ecosystems and economies in the western China. The assessment of drought is of primary importance for water resource planning and management (Mishra and Singh, 2010). Long-term continuous drought could produce a more complex web of impacts on ecology, economy and society. Therefore, understanding multi-scale drought patterns in the western China, which requires knowledge of historical droughts in the region as well as potential factors causing such changes, will be in help for corresponding countermeasures to avoid damage from droughts. The drought patterns identified in this research could support decisionmaking to cope with drought in this region.

Temporal variation patterns of PDSI in the study areas derived from EEMD in this study can be directly used for long-term continuous drought identification and monitoring. Results also revealed that PDSI variations are diverse when different areas are considered, thus suggesting that water conditions vary in different regions. Multi-scale variation patterns of ecosystem functions in these regions should be discussed in future studies to reveal ecosystem responses to long-term drought and to provide the basis of adaptive management.

\section{Conclusion}

Drought patterns in the western China and its two sub-regions during 1951-2012 were explicitly examined using EEMD based on monthly PDSI and atmospheric variables time-series data. Monthly PDSI, as well as monthly time-series of all variables, can be decomposed into eight modes (IMFs) and a trend (RES), indicating that each variable contains eight quasi-period oscillations on various timescales that span seasonal to decadal cycles and a trend through the entire period. However, different dominant frequencies of oscillations were noted for both the arid and semiarid regions, which are apparently controlled by topographies. The controlling atmospheric factors were different when the different regions are considered. Such diversity of drought patterns may have important effects on the responses of various ecosystems in the regions. The multi-scale oscillations of the ecosystems should be discussed in further studies.

\section{Acknowledgments}

This study was supported by the National Basic Research Program of China (2012CB956204) and the National Natural Science Foundation (41371364).

\section{References}

Agwata J F. 2014. A review of some indices used for drought studies. Civil and Environmental Research, 6(2): 14-21.

Alley W M. 1984. The Palmer drought severity index: limitations and assumptions. Journal of Climate and Applied Meteorology, 23(7): 1100-1109.

Bayazit M, Önöz B. 2007. To prewhiten or not to prewhiten in trend analysis? Hydrological Sciences Journal, 52(4): 611-624.

Bhalme H N, Mooley D A. 1980. Large-scale droughts/floods and monsoon circulation. Monthly Weather Review, 108(8): 1197-1211.

Dai A G. 2011a. Drought under global warming: a review. Wiley Interdisciplinary Reviews: Climate Change, 2(1): $45-65$.

Dai A G. 2011b. Characteristics and trends in various forms of the Palmer Drought Severity Index during 1900-2008. Journal of Geophysical Research: Atmospheres (1984-2012), 116(D12): D12115.

Dai A G. 2013. Increasing drought under global warming in observations and models. Nature Climate Change, 3(1): 52-58.

Dai J H, Cui H T. 1999. A review on the studies of alpine timberline. Scientia Geographica Sinica, 19(3): 243-249. (in Chinese)

Ding R S, Kang S Z, Vargas R, et al. 2013. Multiscale spectral analysis of temporal variability in evapotranspiration over irrigated cropland in an arid region. Agricultural Water Management, 130: 79-89.

Fang S F, Yan J W, Che M L, et al. 2013. Climate change and the ecological responses in Xinjiang, China: Model simulations and data analyses. Quaternary International, 311: 108-116.

Geng Q L, Wu P T, Zhang Q F, et al. 2014. Dry/wet climate zoning and delimitation of arid areas of Northwest China based on a data-driven fashion. Journal of Arid Land, 6(3): 287-299.

Giorgi F, Francisco R, Pal J. 2003. Effects of a subgrid-scale topography and land use scheme on the simulation of surface climate 
and hydrology. Part I: Effects of temperature and water vapor disaggregation. Journal of Hydrometeorology, 4(2): 317-333.

Huang J P, Guan X D, Ji F. 2012. Enhanced cold-season warming in semiarid regions. Atmospheric Chemistry and Physics, 12(12): 5391-5398.

Huang N E, Wu Z H. 2008. A review on Hilbert-Huang transform: Method and its applications to geophysical studies. Reviews of Geophysics, 46(2): RG2006.

Huo Z L, Dai X Q, Feng S Y, et al. 2013. Effect of climate change on reference evapotranspiration and aridity index in arid region of China. Journal of Hydrology, 492: 24-34.

Li B F, Chen Y N, Shi X, et al. 2013. Temperature and precipitation changes in different environments in the arid region of northwest China. Theoretical and Applied Climatology, 112(3-4): 589-596.

Li J B, Cook E R, D’arrigo R, et al. 2009. Moisture variability across China and Mongolia: 1951-2005. Climate Dynamics, 32(78): 1173-1186.

Li J B, Gou X H, Cook E R, et al. 2006. Tree-ring based drought reconstruction for the central Tien Shan area in northwest China. Geophysical Research Letters, 33(7): L07715.

Li R, Tsunekawa A, Tsubo M. 2014. Index-based assessment of agricultural drought in a semi-arid region of Inner Mongolia, China. Journal of Arid Land, 6(1): 3-15.

Li S G, Asanuma J, Kotani A, et al. 2007. Evapotranspiration from a Mongolian steppe under grazing and its environmental constraints. Journal of Hydrology, 333(1): 133-143.

Liu M L, Tian H Q, Chen G S, et al. 2008. Effects of land-use and land-cover change on evapotranspiration and water yield in China during 1900-2000. Journal of the American Water Resources Association, 44(5): 1193-1207.

Liu Y H, Feng J M, Ma Z G. 2014. An analysis of historical and future temperature fluctuations over China based on CMIP5 simulations. Advances in Atmospheric Sciences, 31(2): 457-467.

Luo G P, Dai L, Li Y Z, et al. 2011. Prospects on alpine timberline change and its driving mechanism in arid area of Central Asia. Arid Land Geography, 34(6): 873-879. (in Chinese)

McKee T B, Doesken N J, Kleist J. 1993. The relationship of drought frequency and duration to time scales. In: Proceedings of the $8^{\text {th }}$ Conference on Applied Climatology. Boston: American Meteorological Society, 179-183.

McKee T B, Doesken N J, Kleist J. 1995. Drought monitoring with multiple time scales. In: Proceedings of the $9^{\text {th }}$ Conference on Applied Climatology. Boston: American Meteorological Society, 233-236.

Mishra A K, Singh V P. 2010. A review of drought concepts. Journal of Hydrology, 391(1-2): 202-216.

Niemeyer S. 2008. New drought indices. In: López-Francos A. Drought Management: Scientific and Technological Innovations. Zaragoza: International Center for Advanced Mediterranean Agronomic Studies, 267-274.

Palmer W C. 1965. Meteorological drought. Washington: US Department of Commerce.

Palmer W C. 1968. Keeping track of crop moisture conditions, nationwide: The new crop moisture index. Weatherwise, 21(4): 156161.

Qian C, Yan Z W, Wu Z H, et al. 2011. Trends in temperature extremes in association with weather-intraseasonal fluctuations in eastern China. Advances in Atmospheric Sciences, 28(2): 297-309.

Qian C, Zhou T J. 2013. Multidecadal Variability of North China Aridity and Its Relationship to PDO during 1900-2010. Journal of Climate, 27(3): 1210-1222.

Quiring S M, Papakryiakou T N. 2003. An evaluation of agricultural drought indices for the Canadian prairies. Agricultural and Forest Meteorology, 118(1-2): 49-62.

Stocker T F, Dahe Q, Plattner G-K. 2013. Climate Change 2013: The Physical Science Basis. Cambridge, UK, New York, USA: Cambridge University Press.

Titlow J K. 1987. A Precipitation-based Drought Index for the Delaware River Basin. Centerton, NJ. Thornthwaite Associates, Laboratory of Climatology.

Troll C. 1973. The Upper Timberlines in Different Climatic Zones. Arctic and Alpine Research, 5(3): A3-A18.

Van Rooy M P. 1965. A rainfall anomaly index independent of time and space. Notos, 14: 43-48.

Von Storch H. 1999. Misuses of statistical analysis in climate research. In: von Storch H, Navarra A. Analysis of Climate Variability. Berlin Heidelberg: Springer, 11-26.

Wang X P, Zhang L, Fang J Y. 2004. Geographical differences in alpine timberline and its climatic interpretation in China. Acta Geographica Sinica, 59(6): 871-879. (in Chinese)

Wei J, Tao S Y, Zhang Q Y. 2003. Analysis of drought in northern China based on the Palmer severity drought index. Acta Geographica Sinica, 58(Suppl): 91-99. (in Chinese)

Wilhite D A, Glantz M H. 1985. Understanding: the Drought Phenomenon: The Role of Definitions. Water International, 10(3): $111-120$. 
Wu Z H, Huang N E. 2009. Ensemble empirical mode decomposition: a noise-assisted data analysis method. Advances in Adaptive Data Analysis, 1(1): 1-41.

Yue S, Pilon P, Phinney B, et al. 2002. The influence of autocorrelation on the ability to detect trend in hydrological series. Hydrological Processes, 16(9): 1807-1829.

Zavaleta E S, Thomas B D, Chiariello N R, et al. 2003. Plants reverse warming effect on ecosystem water balance. Proceedings of the National Academy of Sciences of the United States of America, 100(17): 9892-9893.

Zhai J Q, Su B D, Krysanova V, et al. 2010. Spatial variation and trends in PDSI and SPI indices and their relation to streamflow in 10 large regions of China. Journal of Climate, 23(3): 649-663.

Zhai P M, Pan X H. 2003. Change in extreme temperature and precipitation over northern China during the second half of the $20^{\text {th }}$ century. Acta Geographica Sinica, 58(Suppl): 1-10.

Zhang Y, Chen F H, Gou X H, et al. 2007. The temporal and spatial distribution of seasonal dry-wet changes over the northwestern China: based on PDSI. Acta Geographica Sinica, 62(11): 1142-1152. (in Chinese)

Zheng C L, Wang Q. 2014. Spatiotemporal variations of reference evapotranspiration in recent five decades in the arid land of northwestern China. Hydrological Processes, 28(25): 6124-6134.

Zou X K, Zhai P M, Zhang Q. 2005. Variations in droughts over China: 1951-2003. Geophysical Research Letters, $32(4)$ : L04707. 